\title{
Keratomycosis complicating pterygium excision
}

This article was published in the following Dove Press journal:

Clinical Ophthalmology

3 October 2011

Number of times this article has been viewed

Harold Merle'

Jérôme Guyomarch'

Jean-Christophe Joyaux'

Maryvonne Dueymes ${ }^{2}$

Angélique Donnio'

Nicole Desbois ${ }^{2}$

'Department of Ophthalmology, ${ }^{2}$ Laboratory of Microbiology, University Hospital of Fort-de-France, Martinique, French West Indies

Correspondence: Harold Merle Service d'Ophtalmologie, Centre Hospitalier Universitaire de

Fort-de-France, Hôpital Pierre

Zobda-Quitman, BP 632, 97261

Fort-de-France Cedex, Martinique,

French West Indies

$\mathrm{Tel}+59659655225 \mathrm{I}$

$\mathrm{Fax}+596596758447$

Email harold.merle@chu-fortdefrance.fr
Abstract: The authors describe a case of keratomycosis that appeared after the exeresis of a pterygium. A 48-year-old patient had been referred with a red right eye associated with an abscess of the cornea along the ablation zone of the pterygium. The surgery had been performed a month beforehand. The abscess was $6 \mathrm{~mm}$ high and $4 \mathrm{~mm}$ wide. The authors instigated a treatment that included amphotericin B $(0.25 \%)$ after noticing a clinical aspect evoking a fungal keratitis and finding several septate filaments on direct examination. On day 10, a Fusarium dimerum was isolated on Sabouraud agar. After 15 days of treatment, the result was favorable and the size of the ulceration as well as the size of the abscess had progressively decreased. The antifungal treatment was definitively stopped at 14 weeks. Infectious-related complications of the pterygium surgery are rare and are essentially caused by bacterial agents. Secondary infections by fungus are rare. There have been two previous cases reported: one that appeared 15 years after radiotherapy and another that appeared at 3 weeks post surgery, consecutive to the use of mitomycin C. To the authors' knowledge, this is the first case of a keratomycosis due to F. dimerum reported that complicated the exeresis of a pterygium without the use of an adjuvant antihealing treatment. Pterygium surgery is a common procedure; nevertheless, ophthalmologists need to be aware of the existence of potential infectious complications.

Keywords: keratitis, corneal abscess, Fusarium

\section{Introduction}

Pterygium is an ocular lesion that is usually benign and is frequent in sunny countries. Surgery is the only curative treatment and there are several operative techniques. The intervention consists of the excision of the pterygium followed by the closing of the exeresis location. Excimer laser, beta irradiation, and antimitotic molecules can be associated with this surgery. ${ }^{1}$ Infectious complications are rare. The authors describe a case of keratomycosis that appeared after the exeresis of a pterygium.

\section{Case presentation}

A 48-year-old patient had been referred for a red right eye, associated with an abscess of the cornea along the ablation zone of the pterygium. Surgery had been performed a month beforehand and had involved the exeresis of a grade 2 recurring nasal pterygium. It was the first recurrence. An autotransplant of the conjunctiva had been used to recover the stripped sclera. No pre-surgery or post-surgery antimitotic molecules had been used. The patient had no specific medical or surgical history. Postsurgical treatment prescribed consisted of indomethacin and neomycin-dexamethasone instillations. The patient did not leave her house, except between days 8 and 15 post 
surgery where she spent some time outside in her garden. On day 25 post surgery, the increase of the secretions as well as the appearance of a white area on the surgical site led the patient to consult her ophthalmologist. The ophthalmologist stopped the local corticotherapy and prescribed ciprofloxacin collyrium and ointment. The symptoms persisted and the patient was referred to the service 4 weeks post surgery. The right eye was red, watery, and selaphobic. The visual acuity was 20/40. There was a $6 \mathrm{~mm}$ high and $4 \mathrm{~mm}$ wide abscess of the cornea around the ablation site of the pterygium. Ulceration with raised edges of about $3 \mathrm{~mm}$ was at the center of the abscess. The main abscess, along with several microabscesses, was located in the temporal region. A discreet proteic Tyndall was noted, as well as folds of the Descemet's membrane of the nasal hemicornea. There was no hypopyon or posterior synechia and no ocular hypertonia (Figure 1). A clinical aspect evoking a fungal keratitis and the revealing of several septate filaments on direct examination led the authors to establish a treatment involving ticarcillin $(7 \mathrm{mg} / \mathrm{mL})$, gentamicin $(15 \mathrm{mg} / \mathrm{mL})$, vancomycin (50 mg/mL), and amphotericin B $(0.25 \%)$. The antifungal treatment was prescribed as follows: one instillation every 5 minutes for 1 hour, then every hour for 3 days, then eight times a day for 2 months, and then, finally, six times a day for 1 month. The authors performed a debridement of the ulceration edges several times. Reinforced collyriums were replaced on day 8 by ciprofloxacin (six times per day) and this was maintained for 15 days. Cycloplegic collyrium was prescribed for 4 weeks and artificial tears for 12 weeks. On

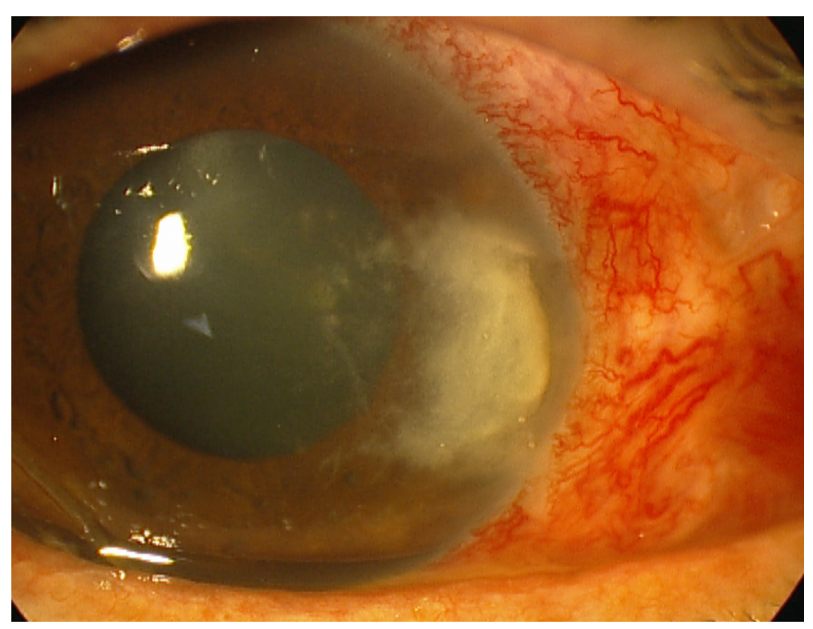

Figure I Abscess of the nasal cornea of the right eye. The abscess, measuring $6 \mathrm{~mm}$ high and $4 \mathrm{~mm}$ wide, was located on the pterygium ablation site. Ulceration with raised edges of about $3 \mathrm{~mm}$ was in the center of the abscess. The abscess was surrounded by infiltrate with irregular and ramified edges, as well as several microabscesses.

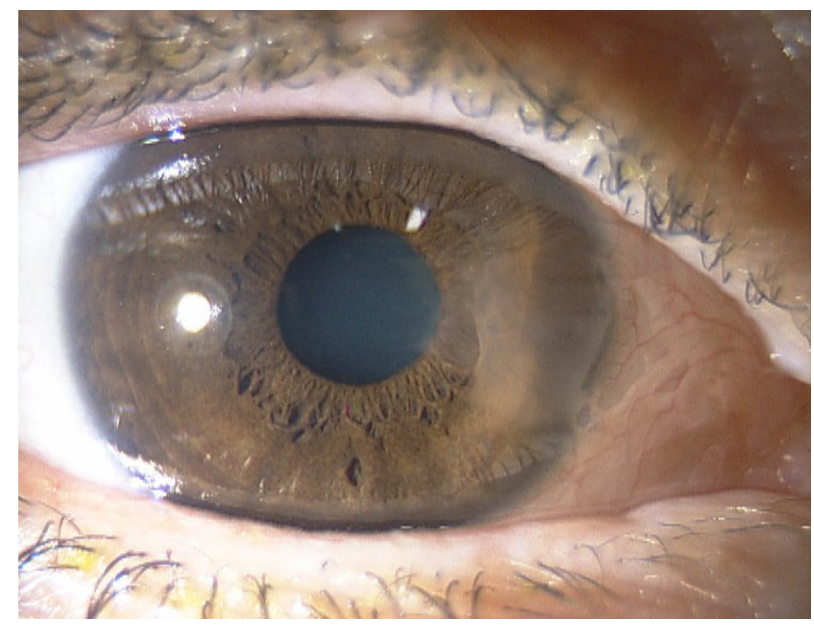

Figure 2 Aspect at 4 months: whitish stromal scar with a big vertical axis and a diameter of about $5 \mathrm{~mm}$.

day 10, a Fusarium dimerum was isolated on the Sabouraud agar. After 15 days of treatment, the evolution was favorable and the size of both the ulceration and the abscess had progressively diminished. The antifungal treatment was stopped at 14 weeks. The abscess was replaced with a whitish stromal scar with a big vertical axis and a diameter of about $5 \mathrm{~mm}$ (Figure 2). There was no more ulceration, but the cornea appeared slimmer within the ablation zone of the head of the pterygium. The visual acuity was 20/25 with astigmatism correction.

\section{Discussion}

Surgery of the pterygium is usually considered as having a low rate of complications of infectious origin. Nevertheless, infectious complications can appear a few days or even a few years post surgery. It essentially concerns bacterial agents; Pseudomonas aeruginosa is the germ that is usually the cause. Other infections by fungus are even more rare; in a study by Lin et $\mathrm{al}^{2}$ of 30 eyes infected after pterygium surgery, only one case of fungal origin (Cephalosporium) was included.

Other than cases reported by Moriarty et $\mathrm{al}^{3}$ (complications appeared 15 years after radiotherapy) and Peponis et $\mathrm{al}^{4}$ (complications appeared 3 weeks post surgery and following use of mitomycin C), to the authors' knowledge, this is the first case of a keratomycosis due to $F$. dimerum reported that complicated the exeresis of a pterygium without the use of an adjuvant anti-healing treatment. In this case, the evolution of the first observation was good, contrary to the second observation when the extension of the infection beyond the ocular structures led to the realization of enucleation. 


\section{Conclusion}

Like pterygium, keratomycosis is more frequent in tropical countries. ${ }^{5}$ The breaking of the corneal epithelium following surgery encouraged the appearance of a mycosis; the gardening undertaken by the patient is the obvious source of a vegetal foreign body. All instances of potential risk related to foreign bodies of any nature, including vegetal, must be avoided until complete re-epithelialization of the corneal ablation site of the pterygium. Although pterygium surgery is a commonly performed procedure, ophthalmologists should be aware of potential infectious complications that can have dramatic outcomes.

\section{Disclosure}

The authors report no conflicts of interest in this work.

\section{References}

1. Alpay A, Ugurbas SH, Erdogan B. Comparing techniques for pterygium surgery. Clin Ophthalmol. 2009;3:69-74.

2. Lin CP, Shih MH, Tsai MC. Clinical experiences of infectious scleral ulceration: a complication of pterygium operation. Br J Ophthalmol. 1997;81:980-983

3. Moriarty AP, Crawford GJ, McAllister IL, Constable IJ. Fungal corneoscleritis complicating beta-irradiation induced scleral necrosis following pterygium excision. Eye (Lond). 1993;7:525-528.

4. Peponis V, Rosenberg P, Chalkiadakis S, Insler M, Amariotakis A. Fungal scleral keratitis and endophthalmitis following pterygium excision. Eur J Ophthalmol. 2009;19:478-480.

5. Donnio A, Van Nuoi ND, Catanese M, Desbois N, Ayéboua L, Merle H. Outbreak of keratomycosis attribuable to Fusarium solani in the French West Indies. Am J Ophthalmol. 2007;143:356-358.
Clinical Ophthalmology

\section{Publish your work in this journal}

Clinical Ophthalmology is an international, peer-reviewed journal covering all subspecialties within ophthalmology. Key topics include: Optometry; Visual science; Pharmacology and drug therapy in eye diseases; Basic Sciences; Primary and Secondary eye care; Patien Safety and Quality of Care Improvements. This journal is indexed on

Submit your manuscript here: http://www.dovepress.com/clinical-ophthalmology-journal

\section{Dovepress}

PubMed Central and CAS, and is the official journal of The Society of Clinical Ophthalmology (SCO). The manuscript management system is completely online and includes a very quick and fair peer-review system, which is all easy to use. Visit http://www.dovepress.com/ testimonials.php to read real quotes from published authors. 